\title{
INTÉRPRETES DE LIBRAS-PORTUGUÊS: DIFICULDADES E DESAFIOS NO CONTEXTO JURÍDICO
}

\section{BRAZILIAN SIGN LANGUAGE-PORTUGUESE INTERPRETERS: DIFFICULTIES AND CHALLENGES IN THE LEGAL CONTEXT}

\author{
Saimon Reckelberg* \\ Silvana Aguiar dos Santos**
}

\section{Resumo}

No Brasil, produções acadêmicas ou iniciativas de profissionalização voltadas a intérpretes de Libras-Português na esfera jurídica ainda são incipientes. Considerando tal contexto, esta pesquisa investiga algumas das dificuldades e desafios enfrentados pelos profissionais que atuam nos serviços de interpretação de Libras-Português, oferecidos pelo sistema judiciário de Florianópolis, Santa Catarina. Para atingir tal objetivo, foi adotada a abordagem qualitativa, de cunho exploratório, tendo como instrumento um questionário aplicado a um grupo de dez intérpretes. Foram utilizados referenciais teóricos da área dos estudos da interpretação jurídica e os resultados da pesquisa, ao evidenciarem os contextos de atuação e as dificuldades enfrentadas pelos intérpretes, podem oferecer subsídios para melhor planejamento e prática da profissionalização de intérpretes de Libras-Português que atuam no campo jurídico.

Palavras-chave: Estudos da Interpretação. Interpretação jurídica. Intérpretes de LibrasPortuguês.

\section{Introdução}

Com as novas políticas de inclusão na área educacional, deu-se maior visibilidade à figura do intérprete de Libras-Português. Frente a essas novas realidades, a educação propicia maior autonomia ao indivíduo surdo, proporcionando-lhe melhor inserção em sociedade. Sujeitos surdos, antes à margem de alguns serviços sociais comuns, conquistam maior

\footnotetext{
* Bacharel em Letras Libras - Língua Brasileira de Sinais pela Universidade Federal de Santa Catarina (UFSC), Tradutor-Intérprete de Libras-Português da UFSC, Santa Catarina. E-mail: saimon.libras@gmail.com

** Doutora em Estudos da Tradução pela Universidade Federal de Santa Catarina (UFSC), professora do Departamento de Língua de Sinais Brasileira (LSB/UFSC) e do Programa de Pós-Graduação em Estudos da Tradução (PGET/UFSC). Professora do Programa de Pós-Graduação em Estudos da Tradução (POET/UFC). Florianópolis, Santa Catarina. E-mail: $\underline{\text { s.santos@ufsc.br }}$
} 
autonomia e podem reivindicar seus direitos linguísticos. As demandas dos surdos criaram espaços de trabalho para o profissional intérprete em diferentes esferas.

Em função da falta de direitos linguísticos assegurados pelo âmbito jurídico, por muitos anos os surdos tiveram dificuldades de acessar os espaços jurídicos, mas hoje reivindicam serviços de tradução e de interpretação também nesses contextos, antes pouco explorados ou não vislumbrados como demandas necessárias de interpretação. A inserção de tradutores e de intérpretes de Libras-Português nesses setores, bem como a capacitação desses mesmos profissionais frente a essas novas demandas, é uma reivindicação dos surdos em todo o país.

O contexto jurídico pode apresentar várias situações em que pessoas surdas estejam envolvidas. Fazer um boletim de ocorrência, requerer benefícios concedidos pela assistência social, deslocar-se a um fórum local, iniciar algum processo civil em órgãos públicos, participar como testemunha, júri ou réu em um tribunal, entre outras situações, são exemplos de serviços e de situações que demandam tradutores ou intérpretes de Libras-Português. Santos (2016, p. 118) amplia essas considerações com alguns outros possíveis contextos de atuação de intérpretes, ao observar que: "Mesmo antes do processo judicial em si, os profissionais podem ser convocados para interpretar outras situações: instrução para investigação, tomada de depoimento em delegacia, assessoria jurídica e outros".

Se, por um lado, o campo profissional no Brasil ainda é emergente e conta com uma série de desafios; por outro, a pesquisa também segue os mesmos rumos. Desse modo, pensando nos desdobramentos e nos contextos de atuação profissional, mas também como campos que podem se tornar objetos de pesquisa nos Estudos da Tradução, trazemos a proposta da Figura 1 a seguir para nortear essa discussão.

Figura 1 - O Contexto Jurídico e seus desdobramentos

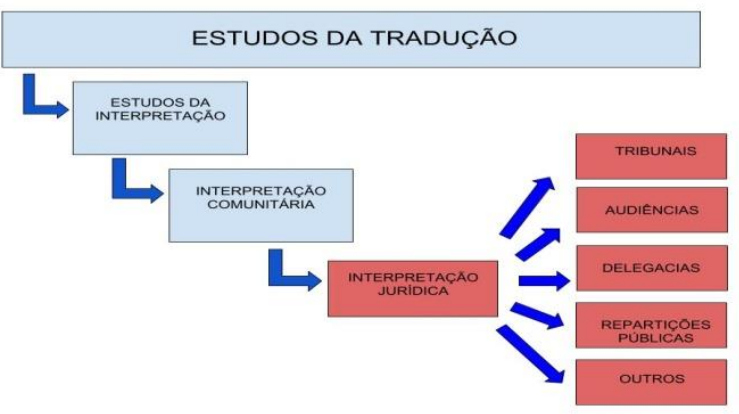

Fonte: Reckelberg (2018, p. 15). 
Cada vez mais a presença de surdos nesses ambientes e, consequentemente, de intérpretes, ressalta a importância de profissionalização, de formação e de pesquisas voltadas para a preparação desses profissionais e para sua atuação, frente às novas demandas, de modo a realizar a interpretação com maior eficiência. É exatamente neste ponto que reside o problema sobre o qual nos debruçamos. Quais são as dificuldades e os desafios apontados pelos intérpretes de Libras-Português que atuam nos contextos jurídicos?

Alguns relatos informais desses profissionais revelam dificuldades com as terminologias usadas, formalidades processuais e protocolos, os quais geram temores e relutância na hora da atuação. Tal situação poderia ser minimizada se tivéssemos cursos de formação e de investimento em pesquisa adequados a esses profissionais. Russel (2002), Roberson, Russel e Shaw (2011), Fonseca (2007) e Santos (2016) são alguns dos autores que abordam a área dos estudos da interpretação jurídica. Com base em seus textos, pretende-se esclarecer algumas questões pertinentes à interpretação de línguas de sinais registradas em contextos jurídicos.

Dessa forma, este artigo desenvolve-se a partir de um diálogo entre os principais referenciais teóricos da interpretação de línguas de sinais no âmbito jurídico. Na sequência, tratamos da construção da pesquisa pautada em uma abordagem qualitativa e de cunho exploratório, tomando como instrumento um questionário aplicado no primeiro semestre de 2018. Por fim, apresentamos a discussão dos dados em que ressaltamos dois resultados principais: os contextos de atuação e as dificuldades enfrentadas pelos intérpretes que atuam na esfera jurídica. Defendemos a ideia de que esses resultados podem oferecer dados úteis para o planejamento e a implementação de ações para a profissionalização de intérpretes de LibrasPortuguês que atuam no campo jurídico, tema também resgatado nas considerações finais.

\section{Diálogos sobre interpretação de línguas de sinais no Judiciário}

Em várias partes do mundo e independentemente dos distintos sistemas jurídicos, a atuação de intérpretes de línguas de sinais no Judiciário tem se deparado com diferentes contextos de trabalho, tais como: tribunais, audiências, delegacias, repartições públicas. Contudo, ainda que tais espaços ofereçam vagas no mercado de trabalho para atuação de profissionais, nem sempre os desafios, as dificuldades e o próprio contexto se tornam objetos de pesquisa. Consequentemente, os diálogos teóricos oriundos de pesquisas empíricas nem sempre se apresentam na mesma velocidade com que proliferam as oportunidades de atuação profissional. O Brasil é um exemplo dessa disparidade entre a atuação profissional e a produção 
acadêmica no que se refere à interpretação de línguas de sinais no Judiciário, pois pouquíssimos trabalhos foram produzidos nos últimos anos, destacando-se: Santos (2016), Gianotto, Manfroi e Marques (2017), Beer (2016), Santos e Beer (2017) e Santos e Sutton-Spence (2018).

Santos (2016) apresenta uma série de questões problemáticas que emergem da atuação de intérpretes de Libras-Português na esfera jurídica e destaca três pontos. O primeiro deles refere-se à diversidade dos meios e dos modos como os profissionais são encaminhados até o Judiciário. Além disso, muitos desses encaminhamentos estão entrelaçados por relações de amizades entre o profissional da interpretação e a pessoa surda, o que colabora para que se perpetue o desconhecimento do papel, das funções e das atribuições de trabalho dos intérpretes de Libras-Português. Um terceiro ponto abordado por Santos (2016) trata das dificuldades com a terminologia específica da área jurídica, enfrentada pelos profissionais da interpretação.

Todas essas observações constatadas por Santos (2016) geram impactos na profissionalização e na institucionalização dos serviços de interpretação de Libras-Português em contextos jurídicos. Os resultados deste trabalho evidenciaram que a prática eficaz de um modus operandi não depende exclusivamente dos intérpretes, mas também da compreensão dos próprios operadores do direito no que tange aos direitos linguísticos das pessoas surdas e do reconhecimento dessas pessoas que acessam o Judiciário.

Por esse viés, os resultados apontados por Gianotto, Manfroi e Marques (2017) contribuíram significativamente para mostrar a perspectiva das comunidades surdas quanto ao acesso ao âmbito jurídico. Os autores apresentam o argumento dos surdos como réus ou vítimas nos tribunais de justiça e discutem os direitos e os desafios legais implicados nessa relação. Em um primeiro momento, os autores debatem sobre o conceito de inclusão e as garantias legais para efetivar essa inclusão. Gianotto, Manfroi e Marques (2017) problematizam os processos criminais no Tribunal de Justiça e no Ministério Público, expondo, na sequência, elementos importantes no julgamento dos surdos no âmbito processual criminalístico. Os autores destacam que:

$\mathrm{O}$ ato interrogatório representa momento ímpar para o réu e para a vítima, notadamente, quando se tratar de um deficiente auditivo. É quando ele pode se declarar de modo a promover sua autodefesa, apresentando sua versão dos fatos. É claro que esse momento representa oportunidade especial para que o magistrado possa criar convicções acerca do interrogado. Salienta-se que o ato interrogatório, pode resultar comprometido quando não há a presença de um competente intérprete de LIBRAS, visto que a pessoa deficiente auditiva não tem em princípio, condições de entender a ritualística estabelecida. (GIANOTTO; MANFROI; MARQUES, 2017, p. 89). 
Gianotto, Manfroi e Marques (2017) compartilham das reflexões apresentadas por Santos, Santos Filho e Oliveira (2010), os quais também defendem a premissa de um julgamento inclusivo nos tribunais de justiça, evidenciando a relevância de que os operadores do direito reconheçam os direitos linguísticos das pessoas surdas. Para atingir esse objetivo, os autores problematizam o significado do termo inclusão nos tribunais de justiça, nas leis brasileiras, e apresentam reflexões sobre o julgamento das pessoas surdas no âmbito processual criminalístico.

Ainda nessa perspectiva, o trabalho de Beer (2016) integra a discussão sobre políticas linguísticas das comunidades surdas no ordenamento jurídico e direitos linguísticos respaldado no aporte dos direitos fundamentais. O argumento central defendido por Beer (2016) mostra como a Teoria dos Direitos Fundamentais "pode ajudar a (re)pensar a questão dos direitos linguísticos, para que estes sejam capazes de impactar e orientar a participação igualitária, ativa e plena dos surdos brasileiros na sociedade atual" (BEER, 2016, p. 3). Todos esses trabalhos apresentados até o momento mostram diferentes e importantes perspectivas que precisam ser consideradas na implementação dos serviços de interpretação de Libras-Português no Judiciário brasileiro.

Inicialmente, a necessidade de uma perspectiva tríade, isto é, contendo o ponto de vista de intérpretes de línguas de sinais, das comunidades surdas e dos operadores do direito foi apresentada por Russel (2002). A autora canadense conduziu uma investigação sobre intérpretes de línguas de sinais na esfera jurídica tomando como base quatro julgamentos simulados. Tal material constituiu a espinha dorsal do livro Interpreting in legal contexts: Consecutive and simultaneous interpretation, o qual concorreu significativamente para a formação de intérpretes de línguas de sinais nessa área. Santos e Beer (2017) contribuíram para a circulação dessa obra no Brasil ao realizarem a resenha desse livro, apresentando um panorama dos temas, dos capítulos e das principais discussões trazidas por Russel (2002).

Santos e Beer (2017, p. 289) destacaram pontos centrais na obra de Russel (2002), dentre eles, o fato de que não somente línguas, mas modalidades diferentes estão implicadas no processo de interpretação de línguas de sinais nos contextos jurídicos. Talvez, a questão da modalidade (interpretação de/para línguas de sinais) possa suscitar ainda mais questionamentos em virtude do desconhecimento, por parte da sociedade e do Judiciário, dos métodos e soluções de trabalho usados por intérpretes de línguas de sinais. Russel $(2002,2005)$ explica que, embora haja quem afirme que intérpretes de línguas de sinais e intérpretes de línguas orais são muito 
diferentes, na verdade, o que os diferencia é a modalidade empregada no processo de interpretação.

Em alguns casos, essas distintas modalidades podem contribuir para crenças equivocadas sobre a atuação dos profissionais. Um exemplo disso pode ser observado no uso da interpretação consecutiva, amplamente disseminada e recomendada como a mais apropriada em algumas situações que ocorrem no ambiente jurídico. $\mathrm{O}$ mito de que apenas os intérpretes de línguas orais estariam aptos a utilizarem o modo consecutivo não se sustenta. Russel (2002, 2005) apresenta resultados de pesquisas realizadas que mostram o papel e a relevância da interpretação consecutiva na formação e no treinamento de intérpretes de línguas de sinais, bem como alguns desafios enfrentados por programas que optam pelo ensino desse modo de interpretação.

Russel (2005) salienta que algumas dessas percepções não são exclusivas dos consumidores dos serviços de interpretação, mas também dos próprios intérpretes que possuem uma compreensão distorcida do uso desse modo de interpretação. Em alguns casos, Russel (2005) discute seus dados de pesquisa com exemplos de depoimentos dos intérpretes que relatam percepções inadequadas, tais como: não levam em consideração a acurácia desse modo de interpretação, alegam que a interpretação consecutiva não é um modo utilizado no mundo real, que a comunidade surda não gosta desse tipo de interpretação, dentre outros elementos. Para Russel (2002, 2005), tanto a comunidade surda quanto os intérpretes poderiam revisar e ressignificar o modo de interpretação consecutivo nas práticas e nas interações realizadas, especialmente na esfera jurídica.

Ainda que Russel (2002) tenha trabalhado com julgamentos simulados, a interpretação consecutiva destacou-se e confirmou a eficácia para usos em tribunais, ao evidenciar a precisão das informações interpretadas nesse âmbito. Obviamente, nem todos os profissionais envolvidos (operadores do direito ou intérpretes de línguas de sinais) na pesquisa de Russel (2002, 2005) concordam com o uso da interpretação consecutiva, mas, ainda assim, tal modo se apresenta como uma importante tomada de decisão das equipes a favor da qualidade dos serviços de interpretação de línguas de sinais. É bastante frequente, nos discursos informais, intérpretes de Libras-Português reclamarem da falta de segurança em realizar a interpretação simultânea em contextos que desconhecem a sinalização das pessoa surdas, especialmente se esta estiver nervosa ou ansiosa perante alguma situação jurídica.

A realidade brasileira depara-se, de forma geral, com uma série de dificuldades e desafios no que tange à profissionalização e, consequentemente, apresenta uma constante 
demanda por formação especializada, tal como a existente em países como Canadá, Estados Unidos e Inglaterra, para mencionar alguns. A implementação dos serviços de interpretação de Libras-Português nos contextos jurídicos, por formação e por profissionalização, não depende exclusivamente dos intérpretes de línguas de sinais, mas de todos os envolvidos. Essa demanda também foi apresentada por Santos e Beer (2017) ao concluírem a resenha do livro de Russell (2002):

[...] ressaltamos que no Brasil o campo da interpretação de Língua Brasileira de Sinais (Libras) para o Português, e vice-versa em contextos jurídicos é incipiente, tanto no que se refere à pesquisa quanto à atuação propriamente dita. Tal área carece de pesquisas que evidenciem as principais demandas, dificuldades e desafios dos intérpretes nesse contexto específico de trabalho. Além disso, a necessidade de formação específica para os intérpretes de Libras-Português que atuam no contexto jurídico é urgente, uma vez que a comunidade surda tem cada vez mais buscado seus direitos (2017, p. 292).

As considerações trazidas por Santos e Beer (2017) dialogam diretamente com as constatações de Rodrigues (2010), que indaga: um único intérprete reuniria as competências, conhecimentos, habilidades e estratégias necessárias ao exercício profissional em esferas distintas? As questões trazidas por Rodrigues (2010), Santos e Beer (2017) entre outros, evidenciam que não basta somente idealizar a formação no plano do discurso, mas definir ações concretas que possam colaborar positivamente com a qualidade dos serviços de interpretação de Libras-Português no âmbito jurídico. Uma das primeiras ações que consideramos importante foi conhecer as experiências, as dificuldades e os desafios enfrentados por intérpretes de línguas de sinais que atuam na esfera jurídica na cidade de Florianópolis. Por esse motivo, na próxima seção, será apresentada a construção do "passo a passo" metodológico desta pesquisa.

\section{Construção do método}

$\mathrm{O}$ acesso à comunicação e às melhorias de acessibilidade comunicacional para as pessoas surdas tem sido um discurso bastante frequente no Judiciário brasileiro. Na maioria dos casos, a concepção que permeia a criação de leis sobre Libras na área jurídica ainda é a da deficiência, da patologia, da surdez e, por conta disso, a necessidade de acessibilidade é um recurso importante dentro dessa vertente. Ao abordarem a tradução e a interpretação de línguas de sinais na esfera jurídica, Rodrigues e Santos (2018) frisam que "é importante que se mencione que o exercício da cidadania de diversas comunidades por meio da garantia de 
direitos linguísticos é uma discussão recente no campo das Ciências Jurídicas” (2018, p. 15). Os autores também discutem sobre as mudanças e as implicações geradas no Judiciário, quando este se propõe a visualizar a língua como um direito linguístico, algo bastante incipiente no país.

Em Florianópolis, na região metropolitana, local de coleta dos dados desta pesquisa, destacam-se diversos órgãos jurídicos, tais como: fóruns, tribunais e delegacias. Contudo, não se tem registros de intérpretes de Libras no quadro de funcionários dessas instituições. De acordo com Reckelberg (2018), ao buscar informações sobre a atuação de intérpretes de LibrasPortuguês nos presídios e nas Casas de Custódia de Florianópolis, obteve-se em resposta ao Ofício $\mathrm{N}^{\mathrm{o}} 0475 / 2018$ os seguintes dados: “dois apenados surdos na região, sendo: (1) Um apenado na Colônia Penal Agrícola de Palhoça, que segundo relatado não se comunica pela língua brasileira de sinais e (2) Um apenado no Complexo Penitenciário do Estado, que nunca utilizou intérprete para se comunicar" (RECKELBERG, 2018, p. 48).

Entretanto, a raridade dos registros de intérpretes de línguas de sinais atuantes nos fóruns, nas delegacias, nos presídios e nas Casas de Custódia de Florianópolis, não quer dizer que a demanda não exista. Por esse motivo, a decisão metodológica neste artigo foi investir em uma pesquisa de abordagem qualitativa, de cunho exploratório que pudesse coletar dados mais precisos sobre a experiência dos intérpretes de Libras-Português que já atuaram nessas instâncias. Sampieri, Colado e Lucio (2012) enumeram as características de uma pesquisa qualitativa e afirmam que ela "permite desenvolver perguntas e hipóteses antes, durante e depois da coleta e análise dos dados" (SAMPIERI; COLADO; LUCIO, 2012, p. 33). Os autores ainda explicam o passo a passo metodológico para o desenho de uma pesquisa qualitativa e, de modo esquemático, sintetizam as principais partes, a saber: ideia, formulação do problema, imersão inicial no campo, concepção do desenho do estudo, definição da amostra inicial do estudo, coleta de dados, análise dos dados, interpretação de resultados, elaboração do relatório de resultados.

Assim sendo, destacamos a questão norteadora deste artigo: Quais são as principais dificuldades e os desafios enfrentados por intérpretes de Libras-Português na prestação de serviços de interpretação ao Judiciário? Para isso, como instrumento de coleta de dados, utilizamos um questionário, o qual foi criado com a ferramenta Formulários Google, encontrada online

A coleta de dados foi realizada nos meses de março e abril de 2018 e, dentre inúmeros intérpretes, nove mostraram-se dispostos a colaborar, os quais responderam ao questionário 
enviado como parte de uma pesquisa de trabalho de conclusão de curso. O questionário continha onze perguntas abertas, justamente para incentivar os participantes a relatarem experiências de interpretação de/para línguas de sinais vivenciadas em tribunais, delegacias, presídios, salas de conciliação e outros. Essas onze perguntas foram distribuídas em quatro seções, a saber: o contexto jurídico e seus desafios, a comunidade surda, o Judiciário e a percepção do intérprete. Neste trabalho, descrevemos e analisamos apenas os dados referentes às dificuldades e aos desafios enfrentados pelos intérpretes de Libras-Português no contexto jurídico.

\section{Discussão dos dados}

O modo como os intérpretes de Libras-Português gerenciam as dificuldades e os desafios enfrentados na prestação de serviços ao Judiciário catarinense pode ser um passo inicial para a profissionalização desse grupo. Registrar práticas, construir rotinas de trabalho e analisar os desafios enfrentados são atividades que podem oferecer indícios concretos para intérpretes que desejam se profissionalizar nesse âmbito; afinal, refletir sobre o fenômeno da interpretação ou, ainda, as decisões tomadas em torno dessa prática são fundamentais para o empoderamento dessa categoria.

Na próxima seção discutimos os dados coletados, tomando como base as respostas dos participantes da pesquisa organizadas em duas categorias, quais sejam: o contexto de atuação de intérpretes de Libras-Português e as dificuldades enfrentadas por esses profissionais na esfera jurídica

\section{Os contextos de atuação de intérpretes de Libras-Português na esfera jurídica}

Para o senso comum, enunciar que os intérpretes de Libras-Português atuam no âmbito jurídico pode ser pouco frequente. A ideia de que o termo "âmbito jurídico" reuniria todos os contextos possíveis de trabalho para os intérpretes é reduzir as possibilidade de trabalho das equipes nesses espaços. Autor e Sutton-Spence (2018) recuperam as contribuições de Mathers (2007) e Napier e Haug (2015) e explicam que a atuação de intérpretes de línguas de sinais não está reduzida ou limitada a tribunais, embora nesses espaços seja comum a presença de intérpretes. Há vários outros contextos possíveis de atuação para esses profissionais. O Gráfico 1 a seguir mostra que alguns participantes preferiram destacar a participação em mais de um contexto, conforme demonstram os resultados. 
Gráfico 1 - Contextos de atuação para intérpretes de Libras-Português na Grande Florianópolis

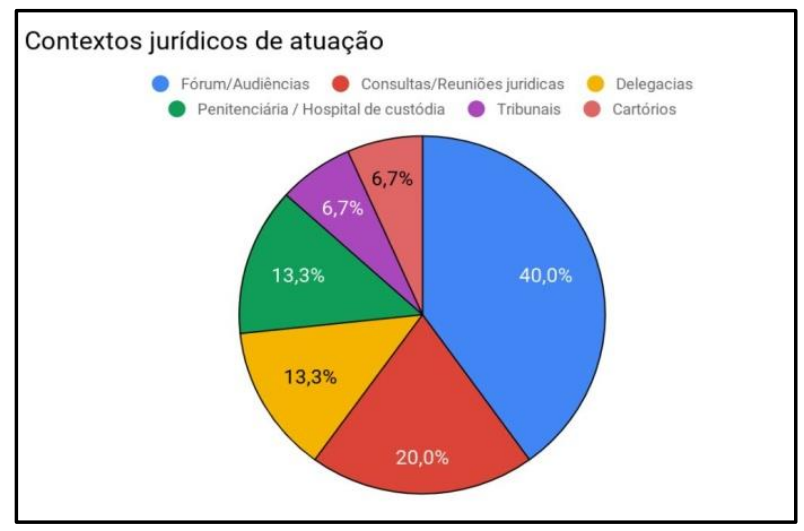

Fonte: Adaptado de Reckelberg (2018).

Como mostra o Gráfico 1, o percentual de intérpretes de Libras-Português na Grande Florianópolis atua com predominância em fóruns, mais especificamente em audiências. Em segundo lugar, destacam-se as consultas, as assessorias e reuniões jurídicas. Com o mesmo percentual de $13 \%$, destacam-se as delegacias e as penitenciárias/hospitais de custódia. Por fim, os cartórios e os tribunais apresentam-se como contextos secundários na pesquisa. Esses dados permitem-nos avançar na discussão em dois aspectos importantes. O primeiro deles, voltado aos protocolos específicos a serem utilizados por intérpretes de Libras-Português em cada um desses contextos. O segundo, refere-se ao entrelaçamento de dois ou mais contextos que não somente o judicial. É fundamental que os intérpretes de Libras-Português observem que cada contexto de atuação apresenta um determinado ritual, ou protocolo a ser seguido, o que exige que os profissionais estejam qualificados para tal. Santos e Sutton-Spence (2018, p. 279-280) explicam que:

No contexto brasileiro, nas delegacias, a tomada de um depoimento é um dos primeiros procedimentos que motiva a instauração de um inquérito policial. Se a equipe de intérpretes não estiver atenta o suficiente para as demandas que podem emergir nesse contexto, algumas dificuldades poderão surgir ao longo da interpretação. Os depoimentos são caracterizados pelo modo narrativo, os quais são expressos pelo depoente.

A demanda para criar documentos que possam nortear os intérpretes atuantes nesse meio é premente. Interpretar em uma audiência não é a mesma coisa que interpretar em uma delegacia, visto que os protocolos são diferentes, bem como as demandas. Quanto mais os 
profissionais estiverem atentos a esses ritos, menos esforços de interpretação eles produzirão; além disso, desenvolverão maior segurança no domínio daquele espaço. Dito de outra forma, conhecer e testar a localização, o equipamento tecnológico para gravação, a estrutura discursiva da audiência ou da delegacia pode contribuir para que os intérpretes conheçam o modus operandi daquele determinado espaço, gerando menos preocupações ou esforços durante o ato da interpretação.

Ademais, vale ainda mencionar o fato de que a esfera jurídica não é isolada em si. Em várias situações, os intérpretes podem estar diante do entrelaçamento de dois ou mais contextos, caso muito comuns nos Hospitais de Custódia ou, ainda, em situações que envolvam audiências com menores de idade, da qual participam psicólogos. Nesta pesquisa, não entramos no detalhamento dos contextos, mas é inegável, por exemplo, que no caso dos Hospitais de Custódia ${ }^{1}$ os contextos de saúde e jurídico estejam imbricados na atuação do intérprete, o que exige dele maior atenção. Rodrigues e Santos (2018, p. 20) explicam que:

A profissionalização nesse âmbito é bastante incipiente, não contando com orientações sobre como serão certificados esses profissionais, com delimitações acerca de sua contratação, com uma descrição das funções que lhes serão atribuídas, ou ainda com definições de seu local de lotação.

Vale ainda mencionar a singularidade de cada contexto ou entrelaçamento de diferentes contextos como ponto importante para que os intérpretes estejam atentos a determinadas demandas. De nada adianta criar um protocolo estipulando posturas, atribuições ou papéis profissionais para A ou B em contextos jurídicos, sem levar em consideração as inúmeras possibilidades de atuação, conforme os diferentes ramos do Direito. Por exemplo, ao se tratar da interpretação de Libras-Português de uma criança surda menor de 10 anos em uma vara da infância, pode ser que os recursos a serem acionados pelos intérpretes de Libras-Português sejam diferentes de situações que envolvam adultos.

Em alguns casos, psicólogos tomam depoimento ou narrativas de crianças em estado vulnerável utilizando-se de dinâmicas específicas da área de psicologia. Nesses casos, o intérprete de Libras-Português deveria ser um agente profissional em cooperação com o psicólogo ou outros profissionais, caso seja necessário facilitar ou mediar situações linguísticas diversas na interpretação em contextos jurídicos. Há relatos informais de alguns intérpretes, por exemplo, que interpretaram da Libras para o Português situações como tomada de depoimento de crianças surdas vítimas de estupro, realizadas por psicólogos que contaram com o uso de desenhos infantis. 
As imagens como recurso semiótico foram altamente exploradas nesse contexto, tema nem sempre trabalhado na formação de intérpretes de Libras-Português. Por esses e outros motivos que, às vezes, as diversas facetas de atuação no contexto jurídico intimidam intérpretes de Libras-Português, algo que se visualizará na próxima seção.

\section{As dificuldades enfrentadas por intérpretes de Libras-Português na esfera jurídica}

Muito se fala sobre os temores envolvendo o Judiciário e a atuação de intérpretes nesse contexto, porém pouco se sabe sobre as percepções e as dificuldades reais enfrentadas por esses profissionais. Na região metropolitana de Florianópolis, em relatos empíricos, é comum intérpretes narrarem certa insegurança ao atuar no âmbito jurídico, especialmente pela falta de terminologias específicas do Judiciário para a Libras, diferentes perfis das pessoas surdas que chegam até aquele ambiente e pelo desconhecimento do papel e atribuições desses profissionais naquela esfera. Assim, ao interrogarmos os participantes da pesquisa referente às dificuldades enfrentadas na esfera jurídica, os dados constatam os seguintes resultados:

Gráfico 2 - Dificuldades apontadas pelos intérpretes no contexto jurídico

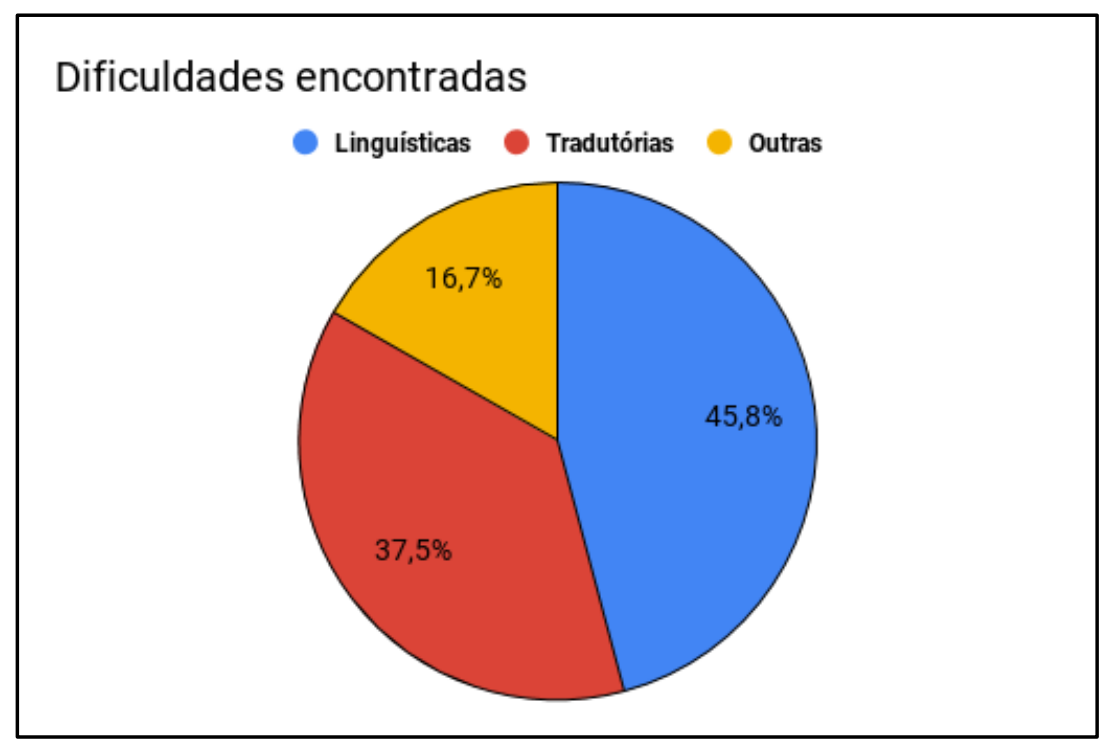

Fonte: Santos e Reckelberg (2019).

O Gráfico 2 registra três principais campos de dificuldades sentidas pelos intérpretes participantes da pesquisa: dificuldades linguísticas, tradutórias e outras. As dificuldades linguísticas abarcam as barreiras enfrentadas quanto à língua portuguesa ou à Libras, como, por exemplo: terminologias usadas, muitas delas advindas do "juridiquês", formalidade do discurso apresentado, falhas de entendimento pelo desconhecimento de um léxico (tanto na direção 
Libras-português quanto vice-versa) e legislação. O uso dessas terminologias, muitas vezes desconhecidas pelos profissionais da interpretação, podem interferir profundamente no processo de recepção do discurso.

As dificuldades tradutórias englobaram elementos como a questão da neutralidade / imparcialidade na interpretação, a falta de revezamento ou de equipes (o fato de, às vezes, ou sempre, o intérprete trabalhar sozinho, sem o auxílio de uma equipe de interpretação ou uma dupla). Ainda, nessa categoria, o desconhecimento do Judiciário em relação ao profissional intérprete foi um dos elementos de destaque apontado pelos profissionais. Uma terceira categoria intitulada por nós como "outras" foi criada para incluir, especialmente, as dificuldades expostas pelos intérpretes, entendidas como temas transversais, por não serem exclusivamente elementos linguísticos ou tradutórios. Em geral, os temas incluídos nessa categoria foram dificuldades de cunho emocional, como, por exemplo, o controle emocional do intérprete frente a determinado contexto jurídico, a sensação de inferioridade no status profissional (em comparação a juízes, advogados e demais autoridades) presentes no ato interpretativo. Além disso, interferências na interpretação por parte de familiares dos cidadãos surdos envolvidos no processo também foi um quesito apontado pelos participantes da pesquisa.

Das três categorias elencadas, aquela envolvida com elementos de ordem linguística se mostrou a mais apontada pelos intérpretes pesquisados, somando 45,8\%. Desse modo, ainda há barreiras linguísticas difíceis de transpor no contexto jurídico, o que pode influenciar e interferir profundamente em uma interpretação.

Em segundo lugar, as dificuldades tradutórias foram as mais citadas pelos participantes, totalizando 37,5\%. Questões de neutralidade, especialmente em casos mais complexos, com vítimas ou testemunhas surdas, são elementos que podem agravar decisões a serem tomadas pelo profissional intérprete, muitas vezes desprovido de condições de trabalho adequadas para tal. A falta de um trabalho em equipe e de remuneração adequada foram fatores reiteradamente mencionados pelos intérpretes, constituindo-se em um dos desafios urgentes a serem discutidos nas ações de profissionalização a favor dessa categoria que atua no âmbito jurídico.

Nesse sentido, tanto no âmbito profissional como no acadêmico, os primeiros trabalhos sobre a importância do trabalho em equipe têm emergido, constituindo-se como argumento central de que as tarefas sejam executadas por dois ou mais intérpretes, tal como afirma Nogueira (2016). No viés profissional, em Nota Técnica nº 02/2017, a Federação Brasileira das Associações dos Profissionais Tradutores e Intérpretes e Guia-Intérpretes de Língua de Sinais

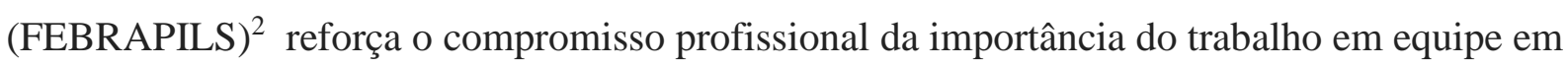


todos os contextos, inclusive sugerindo alternância entre os profissionais para não prejudicar a concentração do intérprete e iniciar-se um processo de fadiga mental, afetando, assim, a produção da mensagem.

Do ponto de vista acadêmico, Gile (1995) foi um pesquisador que se dedicou a uma teoria nomeada "Modelos dos Esforços", a fim de discutir os esforços empregados pelos intérpretes quando estão trabalhando. A partir de sua experiência profissional, como pesquisador da área, problematizou uma série de questões que afetam e atravessam a qualidade e o desempenho dos intérpretes. Gile (1995), Quadros (2004) e Nogueira (2016) ratificam a perspectiva de que, no trabalho de interpretação realizado por apenas uma pessoa, há tendência de ser prejudicada a qualidade da interpretação, em virtude do excessivo esforço cognitivo aplicado.

Elencamos as dificuldades emocionais e o sentimento de inferioridade no status profissional apontado pelos participantes da pesquisa na categoria "outras", totalizando 16,7\%. Além do processo interpretativo em si, esse profissional depara-se com questões emocionais relevantes no exercício de sua função no contexto jurídico. Esse tipo de dificuldade já foi inclusive questionado nas pesquisas de Valero-Garcés (2006) sobre a atuação de intérpretes de línguas orais em contextos comunitários e Albir (2011) quando tratou dos componentes psicofisiológicos. Eles são entendidos como um conjunto de elementos "cognitivos, como a memória, percepção, atenção e emoção; elementos atitudinais de diversos tipos, como curiosidade intelectual, perseverança, rigor, espírito crítico, conhecimento e confiança em suas próprias capacidades, saber medir suas possibilidades e motivação, entre outros" (ALBIR, 2011, p. 396)

Por fim, destacamos um dos principais desafios, que é o de implementar ações concretas na profissionalização dos intérpretes de Libras-Português em nosso país, pois ainda se espera desses profissionais atribuições além daquelas desempenhadas por um intérprete que atua no âmbito jurídico. Um movimento para que o Judiciário visualize a pessoa surda como cidadã em busca de seus direitos linguísticos possibilitará não somente uma virada epistemológica, mas também maior impacto e qualidade nos serviços de tradução e de interpretação de línguas de sinais ofertados no país. 


\section{Considerações finais}

Inicialmente, este artigo propôs-se a realizar uma contextualização breve das pesquisas, das particularidades, das dificuldades e dos desafios envolvidos na atuação dos intérpretes de Libras-Português que trabalham na esfera jurídica. Para tanto, buscamos embasamento nos estudos de Russel (2002), Mathers (2007), Santos (2016) e Gianotto, Manfroi e Marques (2017), dentre outros autores, que abordam especificamente a atuação de intérpretes de línguas de sinais no contexto jurídico, os quais ratificaram a ideia inicial e empírica que motivou a referida pesquisa, a saber: as particularidades e os desafios específicos enfrentados pelo profissional intérprete no contexto jurídico.

Dentre esses autores, no âmbito nacional, Gianotto, Manfroi e Marques (2017) refletiram sobre os direitos linguísticos das pessoas surdas no acesso ao Judiciário, o que impacta o desenvolvimento e o desempenho de intérpretes de línguas de sinais que atuam nesse meio. No âmbito internacional, foram resgatadas as contribuições de Russel (2002) sobre júris simulados e os resultados desses estudos, os quais analisaram diferentes perspectivas (juízes, advogados, intérpretes, testemunhas surdas e outros). Esses elementos foram pertinentes e agregam discussões importantes na atuação de intérpretes de línguas de sinais no contexto jurídico.

Diante desse contexto, foi proposto investigar, por meio de uma abordagem qualitativa, de cunho exploratório, as dificuldades e os desafios que se apresentavam aos intérpretes na região de Florianópolis, usando como instrumento um questionário online. Selecionados dez intérpretes, que já haviam atuado em variados contextos jurídicos, iniciamos um trabalho de coleta das percepções e das sensações desses profissionais. O questionário foi elaborado com perguntas abertas, para que o profissional se sentisse à vontade para expressar-se, comentar experiências e opinar sobre as questões levantadas, o que posteriormente gerou um trabalho de sistematização das respostas e análise dos dados levantados.

A partir das respostas dos participantes, foi possível constatar e ratificar as demandas de formação por contextos especializados na área de interpretação, especialmente no contexto jurídico devido aos principais aspectos: (i) as pesquisas envolvendo esse profissional na esfera jurídica ainda são incipientes no Brasil; (ii) o histórico desse profissional revela uma formação genérica com atuação nos mais variados contextos e situações; (iii) falta de normativas e orientações sobre a atuação profissional de intérpretes de línguas de sinais no contexto jurídico em nosso país. 
Os resultados constataram a necessidade de revisar os contextos de atuação de intérpretes de Libras-Português na esfera jurídica, de modo a ampliar o conceito do que se entende por âmbito jurídico. Além disso, as principais dificuldades enfrentadas por esses profissionais foram classificadas em três categorias (linguísticas, tradutórias e outras). Dessa forma, questões linguísticas, tal como a linguagem de especialidade - o popular "juridiquês" e o perfil do surdo usuário dos serviços de interpretação - compuseram a categoria linguística; assuntos como neutralidade do intérprete e o trabalho em equipe foram agrupados nas questões tradutórias. Por fim, na categoria “outras”, foram incluídas, por exemplo, questões emocionais que afetam o trabalho de interpretação nos diferentes contextos de atuação de intérpretes de línguas de sinais no Judiciário brasileiro.

Sugerimos que as entidades representativas dos intérpretes de Libras-Português em diálogo com as comunidades surdas, com o Judiciário brasileiro e com as instituições de Ensino Superior alinhem medidas para formação por contextos especializados e para investimento de projetos inclusivos que garantam os direitos linguísticos das comunidades surdas do Brasil.

\title{
Notas
}

\footnotetext{
${ }^{1}$ Na região metropolitana de Florianópolis, é comum a convocação de intérpretes de Libras-Português para atuarem nas demandas de interpretação em Hospitais de Custódia.

${ }^{2}$ Nota Técnica no 02/2017 - Nota Técnica sobre a contratação do serviço de interpretação de Libras/Português e Profissionais Intérpretes de Libras/Português. Disponível em: https://drive.google.com/file/d/ 0B3eZNKrWC6hcWnAyd3FIU2VFQmc/view. Acesso em: 20 fev. 2019.
}

\begin{abstract}
In Brazil, academic productions or professionalization initiatives aimed at interpreters of Brazilian Sign Language (Libras) - Portuguese, in the legal sphere, are still incipient. Considering this context, this research investigates the main difficulties and challenges faced by professionals who work in the interpreting services of Libras-Portuguese, offered in the legal system of Florianópolis, Santa Catarina, Brazil. In order to reach this objective, we adopted a qualitative approach, exploratory in nature, having as instrument a questionnaire applied to a group of ten interpreters. Theoretical references from the field of legal interpretation studies were used, and the research results, by highlighting the contexts of performance and the difficulties faced by interpreters, can provide subsidies for better planning and practice of professionalization of interpreters working in the legal field.
\end{abstract}

Keywords: Interpretation studies. Legal interpretation. Interpreters of Brazilian Sign Language-Portuguese. 


\section{Referências}

ALBIR, A. H. Traducción y Traductología. Introducción a la traductología. Madrid: Cátedra, 2011.

BEER, H. Direitos linguísticos como direitos fundamentais: as políticas linguísticas para as comunidades surdas no ordenamento jurídico brasileiro. Trabalho de Conclusão de Curso (Bacharelado em Direito) - Faculdade de Direito, Universidade Federal de Juiz de Fora, Juiz de Fora, 2016. Disponível em: https://repositorio.ufjf.br/jspui/handle/ufjf/3768 Acesso em: 30 ago 2019.

FONSECA, R. T. M. Libras no Judiciário: um débito social. Revista LTr: Legislação do Trabalho, São Paulo, v. 71, n. II, p. 1068-1071, 2007.

GIANOTTO, A. de O.; MANFROI, J.; MARQUES, H. R. Os surdos como réus ou vítimas nos tribunais de justiça: direitos e desafios legais. Educação e Fronteiras On-Line, Dourados, v. 7, n. 19, p. 81-93, jan./abr. 2017.

GILE, D. The Effort Models of Interpreting. In: (org.). Basic concepts and models for interpreter and translator training. Amsterdam/Philadelphia: John Benjamins, 1995. p. 157-190.

MATHERS, C. M. Sign language interpreters in court: Understanding best practices. Bloomington, Indiana: AuthorHouse, 2007.

NAPIER, J.; HAUG, T. A European overview of sign language interpreting provision in legal settings. Dublin: Interesource Group Publishing, 2015.

NOGUEIRA, T. C. Intérpretes de libras-português no contexto de conferência: uma descrição do trabalho em equipe e as formas de apoio na cabine. 2016. $213 \mathrm{f}$. Dissertação (Mestrado em Estudos da Tradução) - Universidade Federal de Santa Catarina, Florianópolis, 2016.

QUADROS, R. M. Secretaria de Educação Especial. Programa Nacional de Apoio à Educação de Surdos. $O$ tradutor e intérprete de língua brasileira de sinais e língua portuguesa. Brasília: MEC; SEESP, 2004.

ROBERSON, L.; RUSSEL, D.; SHAW, R. American Sign Language/English Interpreting in Legal Settings: Current Practices in North America. Journal of Interpretation, v. 21. p. 1-17. 2011.

RODRIGUES, C. H. Da interpretação comunitária à interpretação de conferência: Desafios para formação de intérpretes de língua de sinais. In: CONGRESSO NACIONAL DE PESQUISA EM TRADUÇÃO E INTERPRETAÇÃO DE LÍNGUA DE SINAIS BRASILEIRA, 2., 2010, Florianópolis. Anais eletrônicos...Florianópolis: UFSC, 2010. Disponível em: http://www.congressotils.com.br/anais/anais2010/Carlos\%20Henrique\%20Rodrigues. pdf. Acesso em: 10 fev 2019. 
RODRIGUES, C. H.; SANTOS, S.A. A interpretação e a tradução de/para línguas de sinais: contextos de serviços públicos e suas demandas. Tradução em Revista (Online), São Paulo, v. 24, n.2. p. 1-29, 2018. Acesso em: 20 fev 2019.

RUSSEL, D. L. Interpreting in legal contexts: consecutive and simultaneous interpretation. Burtonsville, MD: Linstock Press, 2002.

Consecutive and simultaneous interpreting. In: JANZEN, T. (Ed.). Topics in signed language interpreting: Theory and practice. Amsterdam/Philadelphia: John Benjamins Publishing, 2005. p. 135-164.

SAMPIERI, R. H.; COLLADO, C. F.; LUCIO, P. B. Metodologia da pesquisa. Porto Alegre: Penso, Grupo A, 2012.

SANTOS, A. M.; SANTOS-FILHO, G. O.; OLIVEIRA, R. Tribunal de Justiça: o julgamento inclusivo dos surdos. Webartigos, 19 maio 2010. Disponível em: http://www.webartigos.com/artigos/tribunal-de-justica-o-julgamento-inclusivo-dossurdos/38094/. Acesso em: 15 out. 2018.

SANTOS, S. A. Questões emergentes sobre a interpretação de Libras-Português na esfera jurídica. Revista Belas Infiéis, Brasília, v. 5, n.1, p. 117-129, 2016. Acesso em: 20 fev.2019.

; BEER, H. Interpreting in legal contexts: Consecutive and simultaneous interpretation. Cadernos de Tradução, Florianópolis, v. 37, n. 2, p. 288-294, maio 2017. Disponível em: <https://periodicos.ufsc.br/index.php/traducao/article/view/21757968.2017v37n2p288>. Acesso em: 24 jan. 2019.

; SUTTON-SPENCE, R. L. A profissionalização de intérpretes de línguas de sinais na esfera jurídica. Translatio, Porto Alegre, v. 1, n.15, p. 264-289, 2018. Acesso em: 20 fev.2019.

VALERO-GARCÉS, C. El impacto psicológico y emocional en los intérpretes y traductores de los servicios públicos Un factor a tener en cuenta. Quaderns. Revista de traducción, Barcelona, v. 13, p. 141-154, 2006. 